\title{
Rede Social e Papéis de Gênero de Casais Ribeirinhos de uma Comunidade Amazônica ${ }^{1}$
}

\author{
Simone Souza da Costa Silva ${ }^{2}$ \\ Fernando Augusto Ramos Pontes \\ Leandro Cavalcante Lima \\ Universidade Federal do Pará \\ Julia Bucher Maluschke \\ Universidade de Fortaleza
}

\begin{abstract}
RESUMO - Este estudo descreve as redes sociais de dois casais de uma comunidade ribeirinha (Rio Araraiana, Município de Ponta de Pedras, Ilha do Marajó/Pará). Os dados foram coletados com um inventário sócio-demográfico, um inventário de rotina e diários de campo e, analisados pelo mapa de rede de Sluzki. Constatou-se que os vínculos dos casais são baseados em alianças de ajuda econômica e de trabalho, companhia para lazer ou atividade religiosa. Verificou-se que as relações são marcadas por padrões de gênero que delimitam os ambientes das atividades cotidianas, definem o status ocupado na família e condicionam a formação de vínculos na rede social.
\end{abstract}

Palavras-chave: casais ribeirinhos; rede social; gênero.

\section{Social Network and Gender Roles of Couples on the Border of an Amazon Community}

\begin{abstract}
This study describes the social network of two couples from a bordering community (Araraiana River, Municipality Ponta de Pedras, Marajó Island/Pará). Data were collected through a socio demographic inventory, a routine inventory and a field diary and analyzed by a network map. It was observed that the relation of the couples is based on economic and work alliances, company for leisure or religious activity. It has also been found that these relationships are marked by gender patterns which delimit the environments of daily activities, define the status that each one holds in the family and condition the formation of bonds in social networks.
\end{abstract}

Keywords: bordering couples; social network; gender.

A discussão sobre as redes sociais é desenvolvida em muitas áreas do conhecimento, tais como informática, lingüística, medicina, sociologia, antropologia, psicologia, etc., havendo uma multiplicidade de conceitos e metodologias de investigação. Meneses e Sarriera (2005) entendem que nas ciências humanas e sociais é possível definir redes sociais como um sistema aberto em permanente construção. São tecidas nas práticas sociais cotidianas e estão associadas aos papéis desempenhados nas relações com outras pessoas ou grupos sociais. Individual ou coletiva, a rede é um conjunto de relações que são fontes de reconhecimento, de sentimento de identidade, da competência e da ação (Meneses e Sarriera, 2005).

Cochran (1990) considera que as redes sociais são constituídas por relações ou elos entre as pessoas, que para Mitchell (1969), são vínculos específicos entre um conjunto definido de sujeitos. Kohn (1977) entende que a rede social de uma

1 Agradeço a valiosa colaboração da equipe de pesquisa do projeto "Contextos de desenvolvimento: família, pares e escola" cuja ajuda na coleta de dados tornou possível a publicação deste artigo: Sarah Danielle Baia da Silva, Daniela Castro Reis, Leila Assef Mendes, Daniele Miranda, Mayara Lima, Abraão Fonseca, Eric Alvarenga e Lorena Santos (todos vinculados ao curso de graduação ou pós-graduação em psicologia da Universidade Federal do Pará).

2 Endereço para correspondência: Condominio Água Cristal, Rua Bejupirá, 39 - CEP: 66635-894. Belém-PA Fone: (091) 32769533 E-mail: symon@ufpa.br pessoa apresenta uma estrutura e um conteúdo determinados pela posição ocupada por esta pessoa e pelas atitudes, valores e habilidades relativas a esta posição. Em acordo com Kohn (1977), Cochran (1990) considera que as redes sofrem influência da cultura, pois esta se organiza de tal forma que delimita o conjunto de relações disponíveis para alguns. Estas redes operariam dentro de um sistema social amplo, sendo influenciadas pelos atributos deste sistema (Wellman, 1981). Portanto, na cultura a rede social de uma pessoa está inserida em ativa e em permanente evolução (Sluzki, 1997, 2000).

No estudo com famílias, Carlos Sluzki se destaca com seu pressuposto conceitual e instrumento de análise para as redes sociais. Ele sustenta uma proposta de descrição da micro-ecologia das relações estabelecidas e percebidas pelas pessoas, vinculando-as às vivencias cotidianas do seu meio microssocial. E fornece meios de identificar o nicho social das relações significativas para o sujeito, isto é, o conjunto de todos aqueles com quem se interage e se distinguem da multidão anônima da sociedade. Para o autor, este "corpo" social é fundamental para a identidade, a história e a experiência individual de bem-estar e de competência, incluindo nesta última os hábitos de cuidado e a capacidade de adaptação em uma crise (Sluzki, 1997, 2000).

No esforço de identificar variáveis que influenciam a organização das redes, Cochran (1990) recomenda a realização 
de pesquisas que relacionem as características da rede pessoal a variáveis como renda familiar, nível educacional e raça do respondente. Fischer (1982) verificou que o nível educacional atua eficazmente sobre as redes sociais. Indivíduos com mais escolaridade e maior renda incluíam mais pessoas em suas redes, provavelmente em função das habilidades decorrentes desta posição social.

Cochran (1990) e Fischer (1982) também consideraram necessário investigar o gênero como fator de influência sobre a organização das redes sociais. Fischer, por exemplo, verificou que mulheres tendem a ser mais envolvidas com os parentes e a descrever mais relações intimas do que os homens. Bott (1957/1976) investigou o modo como os papéis conjugais exercem uma função de conectividade entre redes sociais. Os resultados da autora mostraram que quanto mais diferentes eram os papéis dos casais, mais densas eram as redes de cada cônjuge, sendo tecidas em conformidade com as funções comuns ao mesmo gênero.

As pesquisas sobre relação conjugal destacam o gênero como um fator marcante do modo como a sociedade, a família e seus subsistemas se relacionam (Greenstein, 2000; Narvaz \& Koller, 2006; Therborn, 2006), uma vez que estabelece à priori os papéis e as funções dos cônjuges nestes contextos. Atualmente o debate sobre relações de gênero e organização familiar mostram que estas estruturas vêm mudando.

As modificações nas estruturas familiares e nas relações de gênero são associadas a alterações sociais e econômicas, impulsionadas especialmente pelas mulheres que passaram a ingressar no mercado de trabalho e avançar nos níveis educacionais, assumindo muitas vezes a responsabilidade sobre a subsistência da família (Aizpurúa, Jablonski, \& Féres-Carneiro, 2007; Fleck \& Wagner, 2003; Perucchi \& Beirão, 2007). Assim, novos arranjos familiares emergem e co-existem com o modelo mais tradicional, em que os papéis de gênero estabelecem que homens sejam provedores e chefes de família e mulheres sejam responsáveis pelo espaço doméstico e a educação dos filhos (Amâncio \& Wall, 2006; Monteiro, 2001; Wagner, Predebon, Mosmann \& Verza, 2005).

Henriques, Féres-Carneiro e Magalhães (2006) consideram a existência de três tipos de família na atualidade: a tradicional, caracterizada pela produção econômica conjunta, autoridade paterna, casamento alicerçado em aspectos funcionais e conexões com a comunidade e parentes; a moderna, de estrutura nuclear, é influenciada pelo individualismo, pouco ligada a laços de parentesco e à comunidade e centrada no afeto intrafamiliar; e a pluralística, caracterizada pelos novos arranjos, mais flexíveis e igualitárias e menos permanentes, formadas por mães e filhos ou pais e filhos, por casais recasados com filhos, dentre outras.

Plurais, modernas ou tradicionais, as famílias são expressão do seu contexto sócio-cultural, o qual atribui funções e papéis para homens e mulheres e organiza a estrutura e a dinâmica de suas relações sociais. Isto revela a possibilidade das diferentes formas de organização familiar que negam a idéia de unicidade dos padrões familiares, incompatíveis com um país extenso territorialmente como o Brasil.

Estudos com famílias de áreas rurais (Brumer, 2004; Tedeschi, 2006) destacam a predominância de padrões tra- dicionais de gênero. Todavia, este padrão familiar não tem sido identificado apenas nestes meios, pesquisas revelam que famílias ribeirinhas apresentam uma organização que lembra o que a literatura tem chamado de padrões tradicionais (Baia, 2006; Reis, 2007; Silva, 2006; Silva \& Simonian, 2006; Simonian, 2006).

Assim, este artigo descreve as principais relações estabelecidas e identificadas por dois casais ribeirinhos do Rio Araraiana - Ilha do Marajó/Pará. Estes vínculos são classificados de acordo com as funções relacionais propostas por Sluzki (1997), as quais são discutidas a partir das relações com a micro-ecologia do contexto dos participantes e suas relações de gênero.

\section{Método}

\section{Participantes}

Participaram deste estudo dois casais ribeirinhos do Rio Araraiana. Para fins de manter o anonimato dos participantes, todos os nomes usados neste artigo são fictícios.

\section{Casal Bruno e Marta}

Bruno (30) e Marta (não soube informar) vivem com os filhos Pedro (15), Tais (13), Carla (10), Glória, (8), Inês (5), Nair (3) e Ana (1). Na época da coleta de dados a filha mais velha não morava com a família no Rio Araraiana.

Bruno possui a $1^{\mathrm{a}}$ série do Ensino Fundamental e Marta não freqüentou a escola. O casal e sua família vivem da coleta do açaí, da pesca e de outros produtos extraídos da floresta.

\section{Casal Marcos e Silvia}

Marcos (41) e Silvia (39) vivem com seus quatro filhos, Carlos (12), Eva (14), Paula (16) e Vera (18); Jonas (9), sobrinho do casal; Tito (1 mês), neto; e Omar (não soube informar), genro.

Marcos e Silvia têm a $4^{\text {a }}$ do Ensino Fundamental e vivem da coleta do açaí, da pesca e de outros produtos extraídos da floresta.

\section{Contexto sócio-geográfico}

A pesquisa foi realizada no Rio Araraiana, localizado no município de Ponta de Pedras na Ilha do Marajó, estado do Pará (Amazônia-Brasil). Este rio, de menor expressividade na bacia hidrográfica do município, situa-se a 32,7 milhas náuticas da capital Belém $(68,730 \mathrm{~km})$. É uma comunidade isolada geograficamente dos centros urbanos locais marcada pela ausência de assistência médica ou social.

A comunidade do Araraiana é constituída por 22 famílias com 125 moradores que vivem em palafitas às margens do rio distanciadas entre si cerca de 200 metros. Em geral as casas possuem três cômodos (sala, quarto e cozinha), e são cons- 
truídas com madeira e palhas retiradas das matas adjacentes às habitações. Do rio e da floresta provêm os alimentos e os produtos para a economia extrativista local, como peixe, camarão, caça e açaí. Em termos sociais e religiosos, a população se apresenta dividida em dois grupos: os católicos e os evangélicos. A comunidade conta com dois campos de futebol e uma escola de $1^{\mathrm{a}}$ a $4^{\mathrm{a}}$ série de Ensino Fundamental.

\section{Instrumentos e Técnicas}

Inventário sócio-demográfico (ISD): composto por 88 itens relativos aos seguintes aspectos: a) identificação dos sujeitos pertencentes ao grupo familiar (nome, idade, gênero, parentesco, estado civil, etc.); b) dados demográficos (renda, escolarização, religião, bens, tamanho da residência etc.) e c) aspectos referentes ao modo de vida familiar (modo de sobrevivência, redes de relação extra-familiar, alimentação típica, atividade de lazer, atividades sociais, hábitos de saúde e higiene, etc.).

Inventário de rotina (IR): planilha composta por linhas divididas em quatro períodos do dia (madrugada, manhã, tarde e noite) e por colunas sob as quais foram registradas as interações cotidianas dos participantes (atividades, locais e companhias), ao longo da semana e do fim de semana (domingo).

Observação e Diário de Campo (DC): o pesquisador realizou uma inserção no contexto das rotinas dos participantes para se aproximar e compreender seu universo sócio-cultural. Após cada visita às famílias, as observações eram registras em DC: descrições das pessoas, objetos, lugares, acontecimentos, atividades e conversas vivenciadas durante a coleta de dados; bem como estratégias e reflexões do pesquisador.

\section{Procedimento}

Com a pesquisa aprovada pelo Comitê de Ética sob parecer número 2716-06, iniciou-se um contato com a população mediado por um morador local, aqui denominado de Informante. Profissionalmente, o Informante assume a função de administrador do Hotel-Fazenda onde se situou a base de hospedagem dos pesquisadores. Trata-se de uma pessoa que dispõe de boas relações e liderança entre os habitantes do Rio Araraiana. Após o contato inicial, as famílias visitadas foram informadas sobre o caráter da pesquisa, por meio de um termo de consentimento livre e esclarecido. Em seguida foi aplicado o ISD, para caracterizar a população local e selecionar as famílias para o estudo. O critério de escolha das duas famílias focais foi sua disponibilidade. Nestas famílias foi aplicado com cada um dos membros o IR para a caracterização das interações diárias. Em todas as etapas do contato com as famílias foram redigidos DC.

\section{Análise dos dados}

Para a análise das "redes sociais significativas" dos casais utilizou-se o "Mapa de rede mínimo" proposto por
Sluzki (1997). Este mapa é um diagrama que inclui todos os indivíduos com quem uma pessoa interage, sistematizado em quatro quadrantes que identificam os principais grupos relacionais da rede pessoal: familiares; amigos e conhecidos; relações de trabalho ou de estudo; e relações em organizações formais e informais - social, recreativa, religiosa, política, profissional e de saúde.

Estes quadrantes se organizam tendo como referencia o sujeito da pesquisa. Assim, o círculo mais interno representa o conjunto de relações íntimas, o círculo intermediário se refere a relações pessoais com menor grau de compromisso e, por fim, o círculo mais externo representa o conjunto de relações ocasionais estabelecidas pelo sujeito com pessoas conhecidas. Com base na freqüência dos contatos de cada cônjuge identificada através do IR e nos dados observacionais registrados em diário de campo foi possível alocar os vínculos nos círculos sugeridos por Sluzki classificando-os em: forte (círculo interno), médio (círculo intermediário) e fraco (círculo externo).

Os dados do IR que identificaram as pessoas e o tipo de interação estabelecida com os participantes permitiram descrever: 01) as características estruturais da rede e 02) a função das relações estabelecidas pelos cônjuges. No que se refere às características estruturais, foi possível descrever: a) o tamanho da rede, a saber, o número de pessoas na rede e b) a composição ou distribuição da rede (proporção do total de membros da rede que está localizado em cada quadrante e em cada círculo).

As funções relacionais da rede foram apreendidas não apenas pelo IR, mas também por meio de observações registradas em diários de campo, que serviram como subsídios para qualificar e ilustrar as dimensões funcionais dos vínculos, que conforme Sluzki (1997) são:

Companhia social: realização de atividades conjuntas ou simplesmente o estar junto na rotina cotidiana; Apoio emocional: interações de atitude emocional positiva, ressonância emocional e boa vontade do outro (compreensão, simpatia, empatia, estímulo e apoio); Guia cognitivo e de conselhos: interações caracterizadas por compartilhamento de informações pessoais e sociais, destinadas ao esclarecimento de expectativas e modelos de papéis; Regulação social: interações que lembram e reafirmam responsabilidades e papéis, neutralizam os desvios de comportamento que se afastam de expectativas coletivas; Ajuda material e de serviços: colaboração específica com base em conhecimentos especializados ou ajuda física; Acesso a novos contatos: relações que abrem a possibilidades de novos vínculos com pessoas e redes que até então não faziam parte de rede social do indivíduo.

\section{Resultados}

\section{Casal 1: As redes sociais do casal Bruno e Marta}

Como se observa na Figura 1, a rede de Bruno pode ser considerada extensa, haja vista que é constituída por oito interagentes distribuídos nos quatro quadrantes. No campo 
das relações familiares são apontados a esposa e os filhos que exercem a função de companhia social e de regulação social. Sua rotina revela vínculos fracos com a esposa e a família. Ressalta-se, porém, a relação com o filho Pedro, já que também é identificado como relação de trabalho. Pai e filho passam muitos momentos juntos realizando tarefas para a subsistência alimentar e financeiras da família, trabalhando na mata ou pescando no rio. Portanto, é uma fonte de ajuda nos serviços diários do pai, sendo identificado como um vínculo forte.

No que se refere às relações de amizade, a rede social de Bruno é numerosa. Dois amigos da comunidade se destacam, Gomes que lhe fornece ajuda material e de serviços e Denis como companhia social. O grupo de futebol, assiduamente frequentado por Bruno, é notadamente o espaço de relações onde mais vínculos são identificados, além de possibilitar o acesso a novos contatos - visto que moradores de rios vizinhos participam dos jogos de futebol. Estes vínculos são relatados como força média e, parecem ser mais próximos a Bruno que seus próprios familiares.

Entre as relações comunitárias, identifica-se o casal Carlos e Nilza que proporcionam ajuda material e de serviços, porém são vínculos fracos. Também se verificou o grupo de futebol como uma importante companhia social na rede comunitária. Além de ser um grupo de lazer para Bruno nos finais de semana, o futebol é um espaço de origem e manutenção de relações.

Diferentemente de Bruno, a rede social de Marta, apresentada na Figura 2, é sensivelmente menor e composta apenas por relações familiares. De uma forma geral, a família representa para Marta uma companhia social, com a qual se reúne nos momentos de refeição e à noite para conversar.

Destacam-se, porém, as três filhas mais velhas que lhe são muito próximas (vínculo forte), ligadas a sua rotina pelo auxílio nas tarefas domésticas e no cuidado com as irmãs mais jovens, uma relação marcada pela ajuda material e de serviços. Com o marido Marta apresenta um vínculo fraco, caracterizado como fonte de ajuda material e de serviços na manutenção da família. De fato, ela descreve-o apenas como um bom pai para seus filhos, pois não deixa faltar alimentos para a sobrevivência da família. Um último vínculo a ser destacado é seu pai com quem mantém um fraco vínculo, embora se apresente como fonte de ajuda material e financeira.

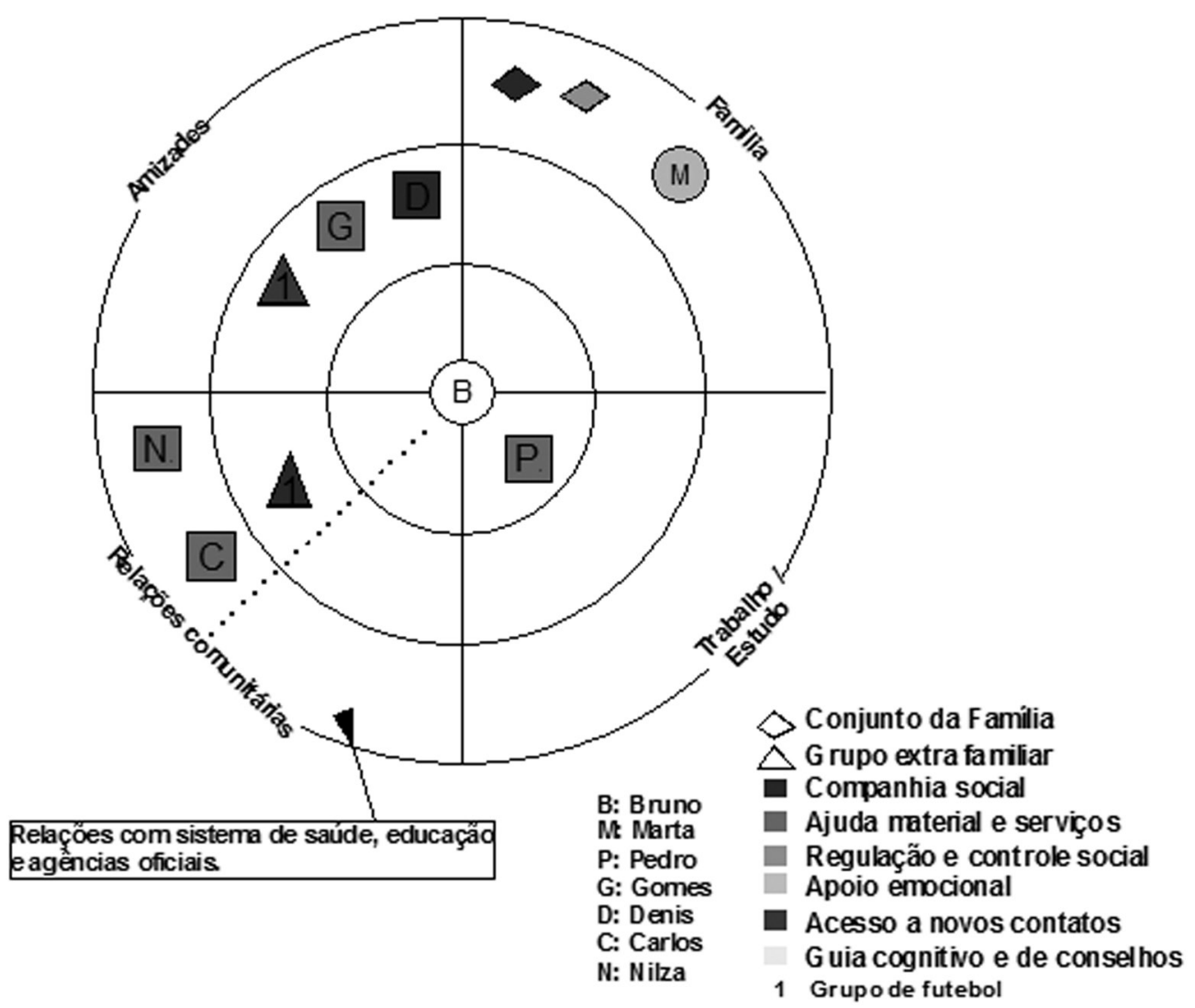

Figura 1. Mapa de rede de Bruno 


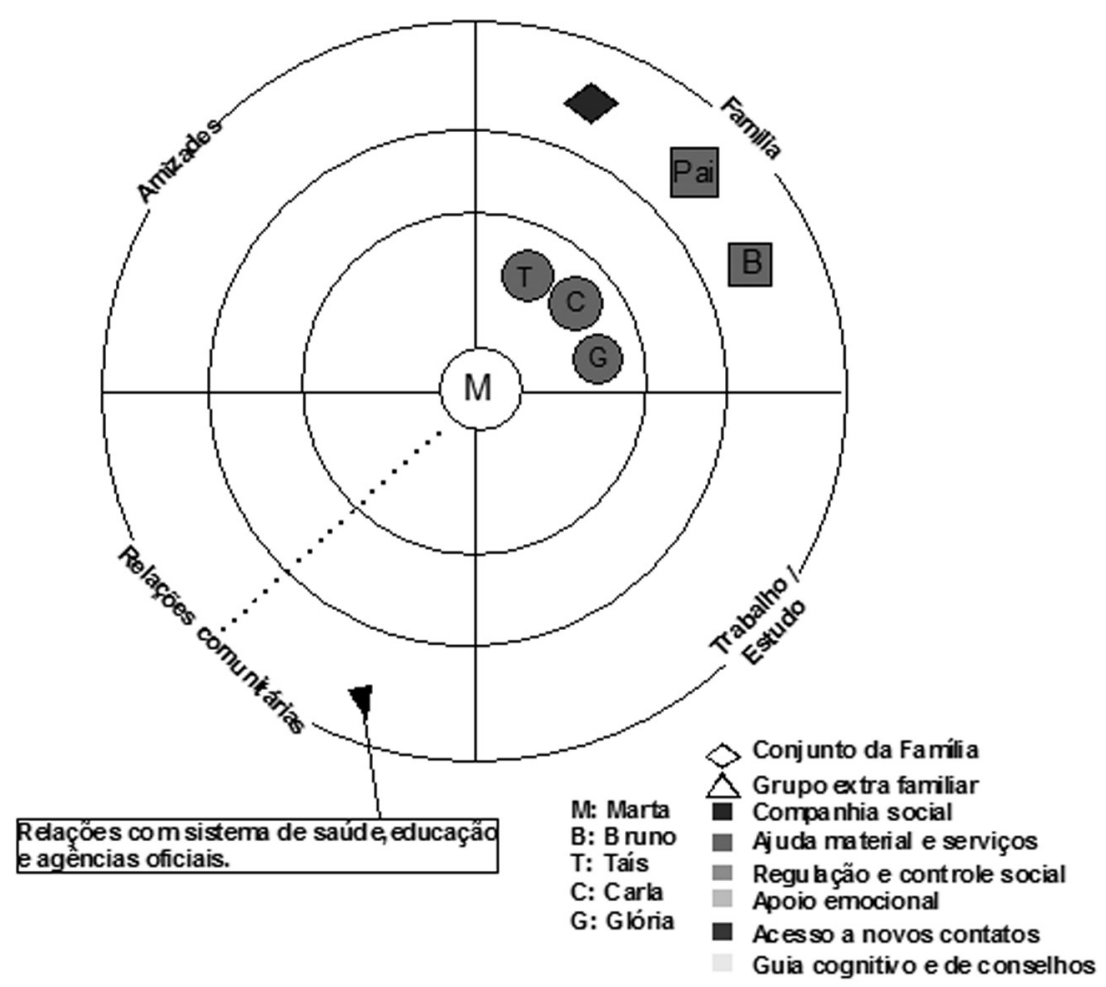

Figura 2. Mapa de rede de Marta

\section{Casal 2: As redes sociais do casal Marcos e Silvia}

A família de Marcos e Silvia é evangélica e se diferencia dos outros moradores do rio pelo forte envolvimento com as atividades religiosas, que ocorrem inclusive em sua casa. Silvia é uma líder dentro do grupo, sendo denominada por alguns de "pastora". Marcos é o dirigente dos cultos do Rio Araraiana, oficialmente é o presbitero local. Para este casal a religião exerce forte influência sobre suas redes sociais.

$\mathrm{Na}$ rede social de Marcos seis interagentes se distribuem nos quatro quadrantes do mapa (ver Figura 3). No campo das relações de amizade se destaca somente Igor, capataz de uma fazenda local e membro do grupo evangélico. É um vínculo classificado como médio, ou seja, de menor compromisso. Caracterizado pela função de ajuda material e de serviços, esta relação é pautada também no auxílio econômico e na troca de bens de consumo.

No campo das relações familiares, a família é identificada como uma companhia social caracterizada como um forte vínculo. O cotidiano de Marcos é repleto de momentos em que todos estão reunidos e conversando, por exemplo, durante as refeições ou no final da tarde. Nos dias de culto religioso, presidido por Marcos, todos costumam participar ativamente: Silvia e os filhos fazem orações, leituras da bíblia e tocam e cantam hinos. Destaca-se o forte vínculo entre Marcos e Silvia, que cumpre a função de conselheira e fonte de apoio emocional.

Referente às relações de trabalho se identifica apenas Omar, seu genro. Um vínculo médio em que a função de ajuda material e de serviços se destaca. Omar mora junto ao sogro e o acompanha nas atividades diárias de extrativismo e de pesca, as quais garantem a subsistência alimentar e econômica da família.

No campo das relações extrafamiliares se identifica o grupo evangélico, com destaque ao pastor que visita a comunidade. Como foi mencionado, Marcos é presbítero local, função que o aproxima dos fiéis (vínculo forte). A relação com este grupo apresenta duas funções: companhia social e acesso a novos contatos. Sem dúvida a comunidade evangélica é uma companhia na rotina de Marcos, especialmente durante os cultos e os momentos de oração. A função de acesso a novos contatos permite novas interações com outras pessoas das redes sociais dos membros do grupo religioso, como outros pastores e missionários que visitam a comunidade.

No grupo evangélico se destaca o pastor, por exercer autoridade sobre o papel religioso de Marcos, cumprindo assim a função de regulação e controle social. É igualmente uma fonte de conselhos (guia cognitivo e de conselhos). A influência do pastor sobre Marcos fica evidente, por exemplo, na crença por este difundida de que jogar futebol é atividade para infiéis. $\mathrm{O}$ vínculo com o pastor é categorizado como forte e exerce impacto direto na rotina social e familiar de Marcos.

A rede social de Silvia apresenta um número maior de interagentes indicados que a rede de Marcos. São oito componentes distribuídos de forma restrita entre às relações em família e com a comunidade evangélica. A diferença encontrada se deve principalmente a função social que exerce de 


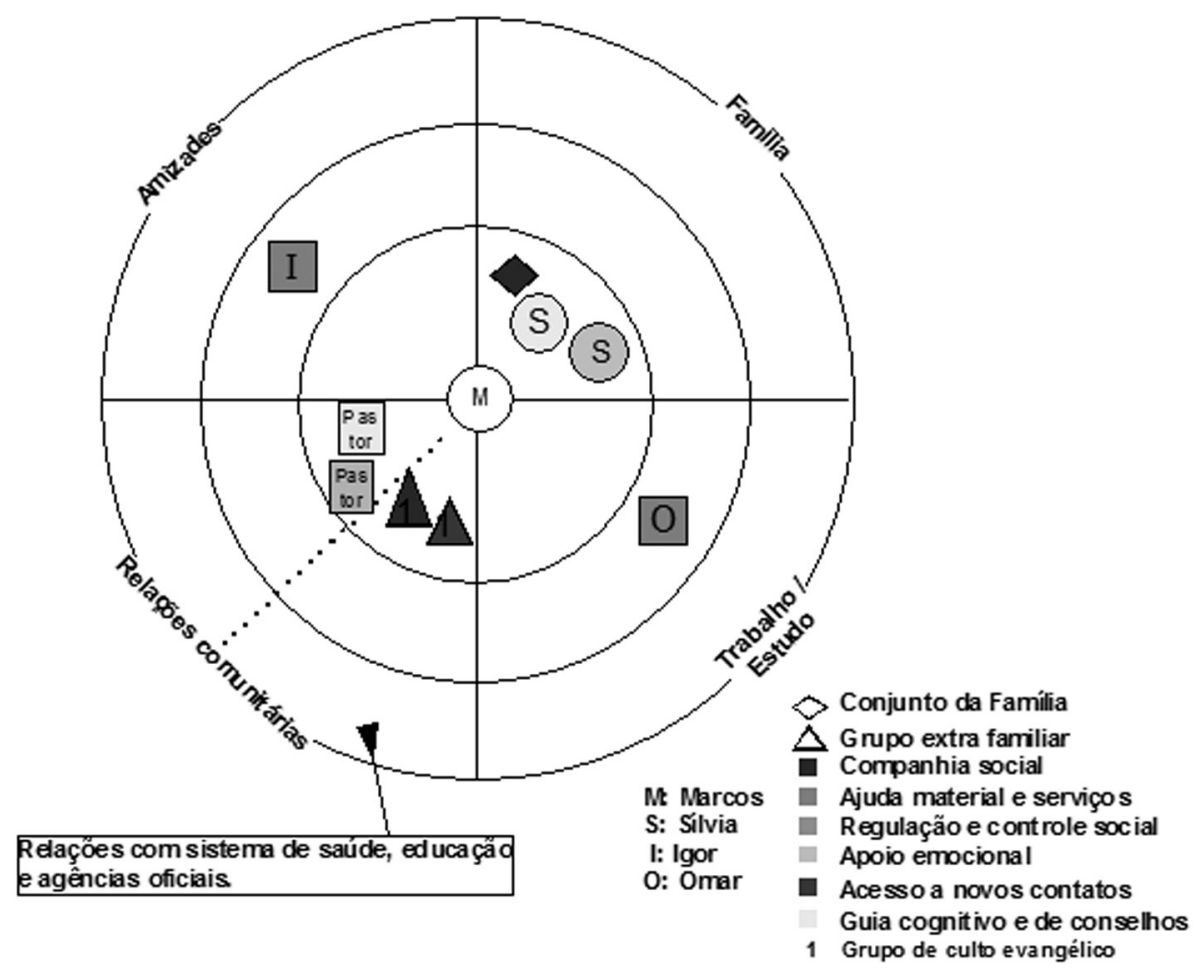

Figura 3. Mapa de rede de Marcos

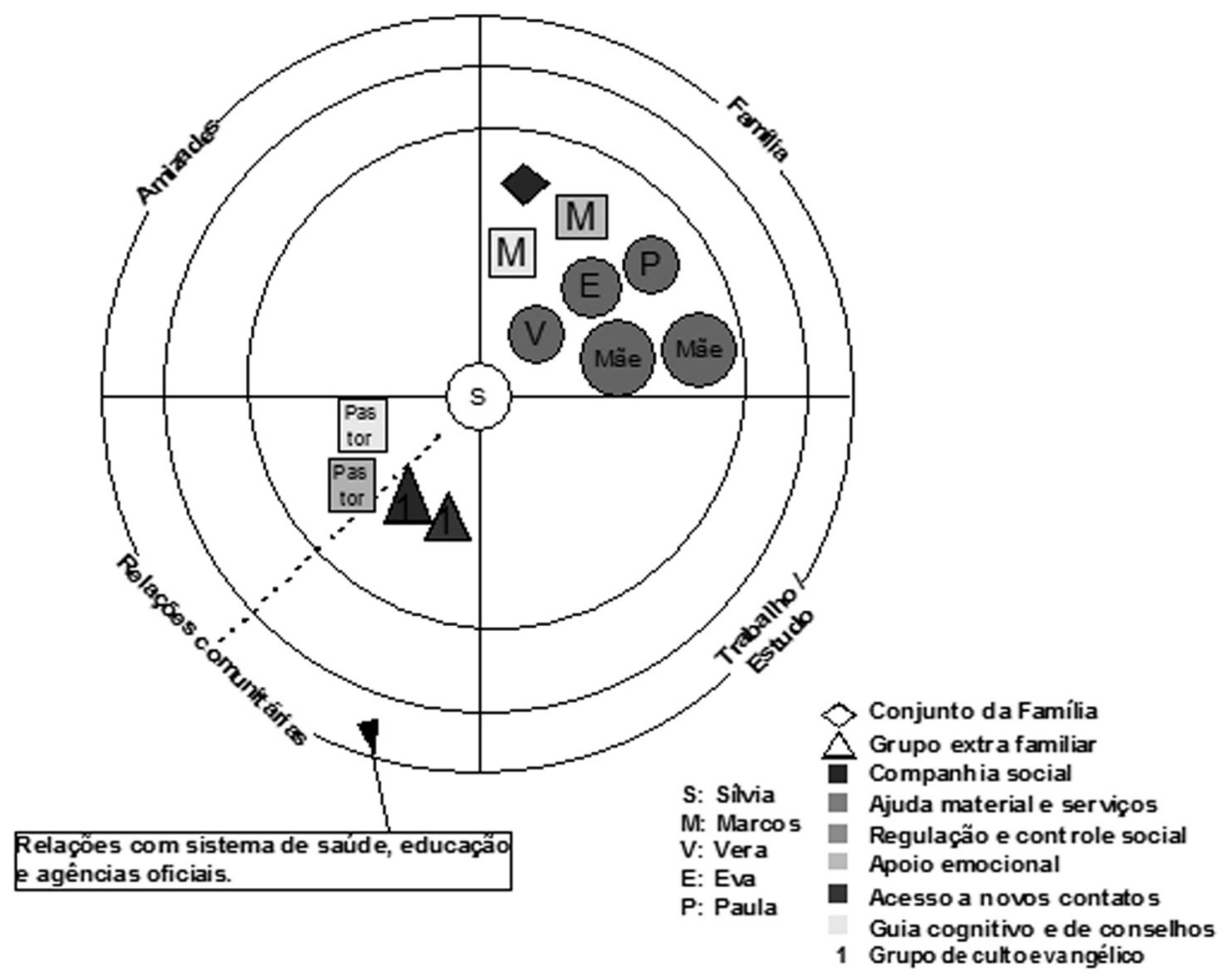

Figura 4. Mapa de rede de Silvia 
líder religiosa e as tarefas cotidianas que a expõem a uma frequência maior de contatos (ver Figura 4).

No campo das relações familiares observamos um forte vínculo com as filhas que são sua principal companhia social e fonte de auxílio nos serviços domésticos, além de sua mãe que vai a sua casa para auxiliá-la nos serviços ou para conversar nos finais de tarde. Destaca-se também, o forte vínculo com Marcos apontado como guia cognitivo e de conselhos e fonte de apoio emocional.

No campo das relações comunitárias destaca-se o forte vínculo com o pastor, um guia cognitivo e de conselhos e que exercer um controle social sobre Silvia, pois também a instrui nos serviços religiosos. Identifica-se, ainda, a comunidade evangélica como forte vínculo e como companhia social e fonte de novos contatos, tal como ocorre com Marcos.

\section{Discussão}

Os mapas de rede dos casais, organizados a partir dos dados de rotina, permitiram identificar que as relações que os cônjuges estabelecem são definidas em função do gênero. Há uma clara divisão de tarefas e de papéis entre homens e mulheres que institui o status ocupado pelos cônjuges e o conjunto de relações possíveis.

Às mulheres cabe a manutenção da família através das tarefas domésticas, como o cuidado com os filhos e do ambiente familiar (casa e adjacências), o preparo de alimento, o cultivo de plantas, a criação de animais, etc. Aos homens, e principalmente aos pais, é destinado o papel de provedor, o comando das atividades econômicas e de subsistência alimentar.

Este modelo tradicional de assimetria entre os gêneros posiciona o homem como o principal provedor e o chefe da família (Amâncio \& Wall, 2006; Greenstein, 2000; Narvaz \& Koller, 2006). Vários estudos têm demonstrado que esses papéis tradicionalmente exercidos por homens vêm perdendo expressão numérica entre famílias do contexto urbano (Fleck \& Wagner, 2003; Monteiro, 2001; Perucchi \& Beirão, 2007; Wagner, Predebon, Mosmann \& Verza, 2005). Diferentemente, na comunidade ribeirinha investigada estes papéis se mantêm. A divisão do trabalho por gênero que se verificou é, sobretudo, voltada à subsistência da família.

Esta estrutura familiar sugere que homens e mulheres são indispensáveis um ao outro no contexto social ribeirinho. De fato, em sociedades tradicionais os casamentos são necessários para a sobrevivência e o papel social da mulher é ser mãe e esposa, como em algumas comunidades da África Oriental (Harkness \& Super, 1992, citado por Rogoff, 2005).

A natureza das ocupações destinadas a cada sexo também define seus espaços de circulação, onde se vivenciam suas relações sociais. Assim, as tarefas femininas restringem a mulher ribeirinha ao contexto do lar, dificultando o contato com pessoas da comunidade e limitando sua rede social a familiares. As atividades extrativistas realizadas pelos homens demandam que saiam para as matas, rios e áreas comunitárias, onde encontra um número maior de companheiros, o que pode justificar o tamanho e a composição das redes masculinas apresentadas.
As diferenças de tarefas e de espaços de convivência de cada cônjuge repercutem na função dos relacionamentos que estes estabelecem na comunidade do rio Araraiana. Neste sentido, os homens e as mulheres se relacionam, na maioria das vezes, com pessoas do mesmo sexo que realizam atividades similares. Este dado corrobora o estudo de Bott (1957/1976) que indicou que quanto mais diferentes eram os papéis dos casais, mais as redes de cada cônjuge eram estabelecidas com pessoas do mesmo sexo; isto porque as redes sociais seriam tecidas com pessoas que exercem os mesmos papéis comuns ao gênero.

Além da influência do gênero, as redes dos casais sofrem a ação de outras variáveis do contexto. Os estudos têm verificado que as características socioeconômicas podem agir sobre o conjunto dos relacionamentos. Tal como a pesquisa de Lever e Martínez (2007), que investigaram a rede social de famílias pobres da Cidade do México, as redes dos casais investigados são constituídas basicamente por familiares e grupos comunitários como a igreja/religião. Portanto, a pobreza que marca o contexto social dos casais estudados pode justificar, em parte, o papel desempenhado pelas relações familiares e comunitárias de ajuda material e de serviços, já que nos casos estudados não existem vínculos com sistema de saúde, educação ou agências oficiais.

É provável que esse padrão de ajuda material e de serviços observado nas relações comunitárias e de amizade seja decorrente da economia de subsistência comum às comunidades da região. A produção das atividades diárias do ribeirinho (pesca, caça, coleta de açaí, etc.) destina-se, essencialmente, ao consumo familiar. $\mathrm{O}$ excedente vendido nos mercados locais visa o sustento da família e não o acumulo de um capital (Miguez, Fraxe \& Witkoski, 2007). Desta forma, é possível que a economia seja uma pressão social para o estabelecimento de relações em que, embora os participantes não sejam muito próximos, favoreçam trocas e ajudas materiais entre vizinhos.

Além dos padrões de gênero estruturados no modo de organização social e econômica da comunidade, considera-se ainda o seu estado de isolamento para a compreensão da organização e dinâmica das redes sociais dos casais. A distância dos centros urbanos e o escasso acesso a veículos de comunicação e a serviços estatais, impõe barreiras relacionais, uma vez que dificulta a formação de vínculos para além da comunidade.

Os efeitos sociais do isolamento lembram as considerações de Cochran (1990), que destaca o papel das redes como uma fonte direta ou indireta de ajuda. Os vínculos de uma rede social são fontes não apenas imediata de benefícios, mas também elos para outras redes igualmente geradoras de ajuda que não estão disponíveis na comunidade estudada. De fato, estas condições limitam as redes sociais dos casais a um conjunto de companheiros da comunidade, que dificilmente serão vias de acesso a novos vínculos.

Embora os estudos sobre as redes de relações sejam encontrados facilmente na literatura, é evidente a escassez de informações referentes a este fenômeno em contextos minoritários como as populações ribeirinhas. Neste sentido, além de permitir o conhecimento acerca deste grupo, os dados do presente trabalho possibilitam tornar estas populações que em geral são invisíveis socialmente, visíveis. 
Pesquisas como estas contribuem na medida em que permitem a construção de políticas públicas compatíveis com o modo de organização social e simbólica dos diferentes grupos sociais, evitando o estabelecimento de ações incipientes que se perdem por falta de sentido real no cotidiano das pessoas. Sendo assim, o conhecimento produzido por pesquisas como estas pode evitar a frustração de gestores e melhorar a qualidade de vida de populações isoladas como a descrita neste artigo.

Além da contribuição social deste estudo, pode-se destacar sua função acadêmica, haja vista que diante do crescente interesse pelas redes sociais, a presente pesquisa apresenta um modo interessante de coleta e análise das redes de relações sociais. Ainda assim, sugere-se que futuras investigações acerca deste fenômeno utilizem-se de estratégias padronizadas e facilmente adaptadas a diferentes contextos como o diagrama da escolta.

\section{Referências}

Aizpurúa, R. L., Jablonski, B., \& Féres-Carneiro, T. (2007). Familias brasileiras y argentinas: entre La tradicion y la modernidad. Revista Interamericana de Psicología, 41(3), 189-196.

Amâncio, L., \& Wall, K. (2006). Família e papéis de género: alguns dados recentes do Family and Gender Survey (ISSP). Lisboa: Working Paper apresentado no Seminário Família e Género em Portugal e na Europa, ICS. Retirado em 25/03/2008, de http:// www.ces.uc.pt/lab2004/pdfs/LigiaAmancio.pdf

Baia, S. D. (2006). Relações entre irmãos e diferenças de gênero em uma comunidade ribeirinha da região amazônica. Dissertação de mestrado, Universidade Federal do Pará, Belém.

Bott, E. (1976). Família e rede social. Rio de Janeiro: F. Alves. (Publicado originalmente em 1957)

Brumer, A. (2004). Gênero e Agricultura: a situação da mulher na agricultura do Rio Grande do Sul. Estudos feministas, 12(1), 205-227.

Cochran, M. (1990). Personal network in the ecology of human development. Em M. Cochran, M. Larner, D. Riley, L. Gunnarson, \& C. R. Henderson Jr. (Eds.), Extending families: the social network of parents and their children (pp.3-33). New York: Cambridge University Pess.

Fleck, A., \& Wagner, A. (2003). A mulher como a principal provedora do sustento econômico familiar. Psicologia em Estudo, 8, 31-38.

Fischer, C. (1982). To dwell among friends: personal network in town and city. Chicago: University of Chicago Press.

Greenstein, T. N. (2000). Economic dependence, gender and the division of labor in home: a replication and extension. Journal of Marriage and Family, 62(2), 322-335.

Henriques, C. R., Féres-Carneiro, T., \& Magalhães, A. S. (2006). Trabalho e família: o prolongamento da convivência familiar em questão. Paidéia, 16(35), 327-336.

Kohn, M. (1977). Class and conformity: a study in values. Chicago: University of Chicago Press.

Lever, J. P., \& Martínez, Y. I. C. (2007). Pobreza y apoyo social: un estudio comparativo en tres niveles socioeconómicos. Interamerican Journal of Psychology, 41(2), 177-188.

Meneses, M. P. R., \& Sarriera, J. C. (2005). Redes sociais na investigação psicossocial. Aletheia, 21, 53-67.
Mitchell, J. C. (1969). The concept and use of social network. Em J. C. Mitchell (Ed.), Social network in urban situations. Manchester, U.K.: Manchester University Press.

Miguez, S. F., Fraxe, T. J. P. E., \& Witkoski, A. C. (2007). $O$ tradicional e o moderno na agricultura familiar amazonense: a introdução de tecnologias em comunidades de várzea no rio Solimões, Amazonas. Retirado em 20/12/2007, de www.cnpat. embrapa.br/sbsp/anais/Trab_Format_PDF/96.pdf

Monteiro, A. M. (2001). Avanços no estudo da conjugalidade: os casais de dupla carreira. Psicologia: Ciência e Profissão, 21(3), 10-19.

Narvaz, M. G., \& Koller, S. H. (2006). Famílias e patriarcado: da prescrição normativa à subversão criativa. Psicologia $e$ Sociedade, 18 (1), 49-55.

Perucchi, J., \& Beirão, A. M. (2007). Novos arranjos familiares: paternidade, parentalidade e relações de gênero sob o olhar de mulheres chefes de família. Psicologia Clínica, 19(2), 57-69.

Reis, D. C. (2007). Cultura da brincadeira em uma comunidade ribeirinha na ilha do Marajó. Dissertação de mestrado, Universidade Federal do Pará, Belém.

Rogoff, B. (2005). Transição nos papéis dos indivíduos em suas comunidades ao longo do desenvolvimento. Em B. Rogoff (Org.), A natureza cultural do desenvolvimento humano (pp.129-162). Porto Alegre: ArtMed.

Silva, S. S. C. (2006). Estrutura e Dinâmica das relações familiares de uma comunidade ribeirinha da região amazônica. Tese de doutorado, Universidade de Brasília, Brasília.

Silva, C. N., \& Simonian, L. T. L. (2006). A questão de gênero: um breve estudo no estuário Amazônico. Papers do NAEA (UFPA), 1, 1-17.

Simonian, L. T. L. (2006). Pescadoras de camarão: gênero, mobilização e sustentabilidade na ilha Trambioca, Barcarena, Pará. Boletim do Museu Paraense Emílio Goeldi, 1(2), 35-52.

Sluzki, C. E. (1997). A rede social na prática sistêmica: alternativas terapêticas. São Paulo: Casa do Psicólogo.

Sluzki, C. E. (2000). Social network and the elderly: conceptual and clinical issues, and a family consultation. Family Process, 39(3), 271-284.

Tedeschi, L. A. (2006). Meu nome é ajuda: a vida cotidiana e as relações de poder, gênero e trabalho das mulheres trabalhadoras rurais na região noroeste do Rio Grande do Sul. Contexto \& Educação, 1(1), 45-64.

Therborn, G. (2006). Sexo e poder: a família no mundo, 1990-2000. São Paulo: Contexto.

Wagner, A., Predebon, J., Mosmann, C., \& Verza, F. (2005). Compartilhar tarefas? Papéis e funções de pai e mãe na família contemporânea. Psicologia: Teoria e Pesquisa, 21, 181-186.

Wellman, B. (1981). Applying network analysis to the study of support. Em B.H. Gottlieb (Ed.), Social network and social support. Beverly Hills, Cal.: Sage.

Recebido em 25.11.08

Primeira decisão editorial em 29.09.09

Versão final em 17.11.09

Aceito em 04.02.10 